\title{
INCOME INEQUALITY TRENDS IN THE 1980s AND 1990s
}

Ann Harding

Director, National Centre for Social and Economic Modelling

University of Canberra

This article describes trends in income inequality in Australia during the past two decades, primarily using the income distribution survey unit record tapes released by the Australian Bureau of Statistics for 1982 and 199697. There has been little change in national overall inequality during this period. But this lack of overall change at the national level disguises two major trends:

- better outcomes for the poor and the rich than for middle Australia;

- an apparent increase in spatial income inequality (that is, inequality of income by geographical regions).

As always, there is considerable debate about trends in income inequality in Australia. The popular perception is that 'the rich have got richer and the poor have got poorer'. But once the most appropriate methods are used for analysing income inequality, the evidence does not bear this out.

Two issues are particularly important when analysing trends in income inequality. The first is that total (gross) income is not the best measure of income to use, because it does not take account of the equalising effect of income tax. Our income tax system is progressive, which means that it takes a higher proportion of the income of the rich than of the poor, so it is important to include it within the distributional picture. Thus, most income inequality experts prefer to use disposable income as their measure of economic wellbeing. This equals private income, plus government cash transfers (such as age pension), minus income tax.

The second issue is that it is important to look at equivalent income and rank families by their equivalent income. Equivalent income is calculated as a means to more accurately compare the relative economic wellbeing of families with different needs. Such scales recognise, for example, that a single person with an income of $\$ 20,000$ is in a better position than a couple with three children with an income of $\$ 20,000$. There is not, however, any agreement within Australia or internationally about the exact needs of different types of families and thus about the 'best' equivalence scale to use. The analysis below uses the detailed Henderson equivalence scales, developed by the Henderson poverty inquiry in the mid-1970s.

\section{THE OVERALL PICTURE}

Aggregate inequality measures attempt to describe in a single summary statistic the state of income inequality in a country. Gini coefficients are one measure of the change in aggregate income inequality. The Gini varies between 0 (absolute equality) and 1 (one family has everything).

The Gini coefficients in Table 1 suggest sharp increases in the inequality of investment, wage and earned income between 1982 and 1996-97. Government cash benefits became more progressive over this period, so the rise in government transfers (that is, the age and disability pensions, unemployment benefits, etc.) helped to offset

\section{FIGURE 1}

AVERAGE REAL DOLLAR AND PERCENTAGE CHANGES IN EQUIVALENT FAMILY INCOME, AUSTRALIA 1982 TO 1996-97

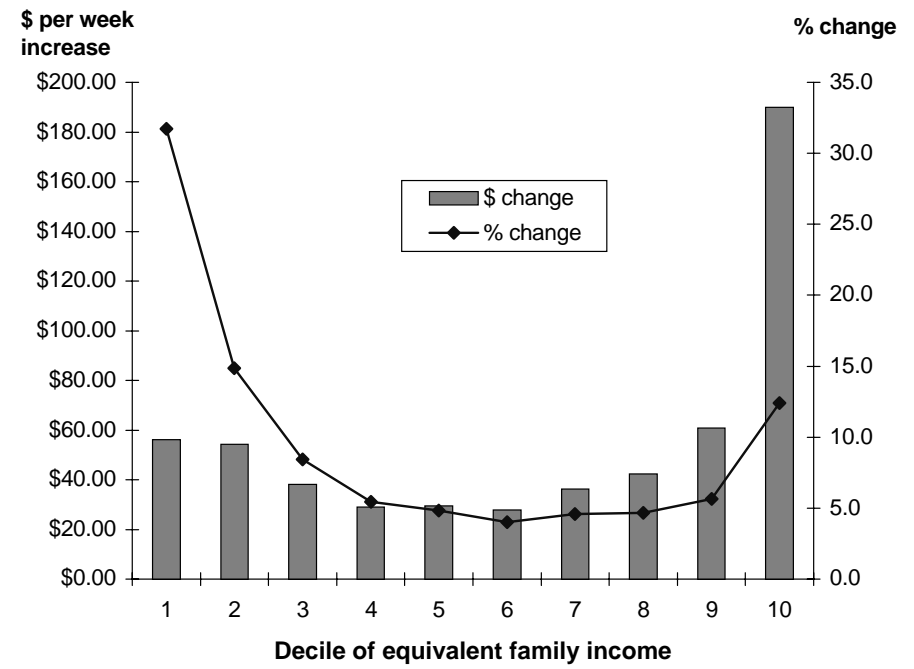


TABLE 1

GINI COEFFICIENTS FOR A RANGE OF INCOME MEASURES, AUSTRALIA, 1982 AND 1996-97

\begin{tabular}{|lcccc|}
\hline & $\mathbf{1 9 8 2}$ & $\mathbf{1 9 9 6 - 9 7}$ & $\begin{array}{c}\text { Change 1982 } \\
\text { to 1996-97 }\end{array}$ & Verdict \\
\hline Investment Income & 0.896 & 0.922 & 0.026 & Sharp inequality increase \\
Wage Income & 0.547 & 0.573 & 0.026 & Sharp inequality increase \\
Earned Income (incl own business) & 0.477 & 0.538 & 0.061 & Sharp inequality increase \\
Private Income & 0.457 & 0.511 & 0.054 & Sharp inequality increase \\
Total Income & 0.386 & 0.398 & 0.012 & Inequality increase \\
Tax (concentration coefficient) * & 0.582 & 0.615 & 0.033 & More progressive \\
Disposable Income & 0.337 & 0.346 & 0.009 & Little change \\
Henderson Equivalent Income & 0.290 & 0.287 & -0.003 & No change \\
\hline * The inequality measure for tax is called the 'concentration coefficient', and an increase in this measure \\
\multicolumn{2}{l}{ means that taxes are becoming more progressive (that is, higher tax rates for higher income earners). }
\end{tabular}

the growing inequality of private income produced by the market. The rise in the Gini for total income was thus much less substantial than that for private income.

Income taxes also became more progressive during this period, so that income taxes helped to further offset the growing market-based inequality. Thus, the Gini for disposable income (that is, after receipt of government transfers and payment of income tax) remained roughly the same.

After taking account of the needs of families using an equivalence scale, the results suggest that overall income inequality remained much the same in 1982 and 199697.

\section{THE SUFFERING MIDDLE}

Figure 1 shows the final trends in income from 1982 to 1996-97, after taking account of trends in private income, government cash benefits, income tax, and changing family size. ${ }^{1}$ Overall, the results suggest that on average all deciles had higher equivalent incomes in 1996-97 than in 1982. However, those at the bottom and those at the top had higher real dollar increases than those in the middle.

A slightly different impression is given if these real gains are looked at as a percentage. Then the lowest two deciles have higher percentage gains than the middle and top deciles. In other words, even though the top decile makes substantial dollar gains, these amount to less than a 15 per cent increase in their equivalent disposable incomes between 1982 and 1996-97 (Figure 1).

Why is the bottom decile apparently doing so well? The composition of the bottom decile changed between 1982 and 1996-97, with many sole parents and couples with children moving out and up as a result of generous family assistance reforms. They were replaced by couples without children, the aged and single people. Lower unemployment rates for the bottom decile played an important part, with 29.3 per cent of all individuals in the bottom decile living in families where someone was unemployed in 1982, versus only 26.4 per cent in 199697. In 1982 single employed people made up 5.2 per cent of the bottom decile; by 1996-97 this was up to 9.6 per cent. The average number of earners per family in the bottom decile increased from 0.59 in 1982 to 0.62 in 1996-97. This 0.03 increase in the number of earners was in sharp contrast to the average fall of 0.01 earners per family for the population as a whole. Thus, to some extent, social security dependent families with children moved out of the bottom decile and were replaced by the working poor.

\section{REGIONAL INCOMETRENDS}

There is growing evidence that the picture of no overall national change in income inequality is also disguising growing spatial divisions. Using census data, for example,

\section{FIGURE 2}

SHARE OF TOTAL EQUIVALENT GROSS HOUSEHOLD INCOME RECEIVED BY EACH DECILE OF AUSTRALIANS (RANKED BY THE EQUIVALENT GROSS HOUSEHOLD INCOME OF THE LGA IN WHICHTHEY LIVED)

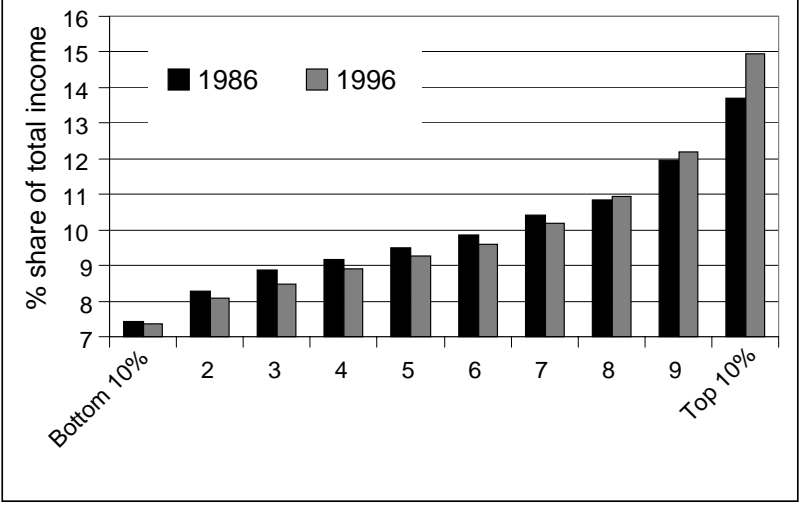


Lloyd et al. recently found that income growth over the 1991 to 1996 period was roughly twice as rapid in the capital cities as in most other areas of Australia. ${ }^{2}$ The proportion of low income households has been increasing somewhat more rapidly outside the cities.

In Figure 2, all Australians have been ranked by the equivalent gross household income of the local government area in which they live (using the OECD equivalence scale). The bottom decile thus consists of the 10 per cent of Australians who lived in the poorest local government areas. The results suggest that the 10 per cent of Australians living in the most affluent local government areas gained over the 10 years to 1996, with their share of the total income pie increasing by 1.26 percentage points to 14.96 per cent. Overall, the 30 per cent of Australians living in the top three deciles of local government areas increased their share of the total pie. In contrast, the 70 per cent of Australians living in middle and lower income local government areas lost ground, seeing their share of the total income pie shrinking from 63.5 per cent to 61.91 per cent. There is thus some evidence that already rich neighbourhoods are becoming even richer, while poorer neighbourhoods are becoming even poorer.

\section{CONCLUSION}

There has been little change in national overall inequality during this period. But this lack of overall change at the national level disguises two major trends: better outcomes for the poor and the rich than for middle Australia; and an apparent increase in spatial income inequality (that is, inequality of income by geographical regions).

\section{REFERENCES}

1. Harding A. The Suffering Middle: Trends in Income Inequality in Australia 1982 to 1993-94. Australian Economic Review December 1997; 30 (4).

2. Lloyd R, Harding A and Hellwig O. Regional Divide? A Study of Incomes in Regional Australia: Discussion Paper No. 51. Canberra: National Centre for Social and Economic Modelling, September 2000; 5. Downloadable from www.natsem.canberra.edu.au.

\section{PROMOTION, PREVENTION AND EARLY INTERVENTION IN MENTAL HEALTH: TWO NEW NATIONAL DOCUMENTS}

\author{
Kym Scanlon, Beverley Raphael and Kathy Paterson \\ Centre for Mental Health \\ NSW Department of Health
}

Mental health has been identified as a key priority area by NSW Health and also nationally. Recent documents have highlighted the increasing burden imposed by mental health problems and disorders in our society. Depression alone has been predicted as one of the greatest problems internationally by the year $2020 .{ }^{1}$ Promotion, prevention and early intervention for mental health has been identified as important to progress, in order to diminish this burden. There is growing evidence that effective promotion, prevention and early intervention initiatives can reduce the prevalence of mental health problems, and lessen the severity and duration of mental illness. ${ }^{2,3,4}$

The National Action Plan for Promotion, Prevention and Early Intervention for Mental Health 2000, 5 and an accompanying Promotion, Prevention and Early Intervention for Mental Health 2000: A Monograph, ${ }^{6}$ were released in late 2000 . These two documents have been developed by the National Promotion and Prevention Working Party, which has representation from the National Mental Health Working Group and the National Public Health Partnership.

Together these documents provide a strategic framework and a plan for action to address promotion, prevention and early intervention priorities and mental health outcomes across Australia. The monograph provides the theoretical and conceptual framework and background information for the action plan.

To support the implementation of the National Action Plan, a New South Wales Promotion, Prevention and Early Intervention Steering Committee has been appointed. Consultation forums to guide implementation are occurring in the area health services across NSW, with 600 people participating in these to date.

Copies of Action Plan 2000 (ISBN 0642 447241) and the Monograph (ISBN 0642 44725X) are available from the Better Health Centre, telephone: (02) 9816 0452; fax: (02) 9816 0492. Feedback on the documents can be provided through a form enclosed at the back of these documents. 